\title{
AN APPROACH TO IMPROVE LOCAL BUS STOPS IN THE INNER-CITY OF KARACHI
}

\author{
Humaira Nazir*
}

\begin{abstract}
Public spaces are an important part of human life. These spaces account for the intellectual growth of individuals and invoke a spirit of their own. Everybody can access these places any time of the day. Sidewalks, streets, markets, parks, recreational spaces, public squares and bus stops come under the category of public spaces.

Most bus stops in a city remain vibrant throughout the day. All sorts of people and activities can be observed at bus stops. Despite the need and importance of bus stops, they are often poorly integrated or neglected and are not given the attention that makes them successful public and active social gathering space. The purpose of this study is to explore how to improve the present condition of public bus stops so that the use increases, and they become welcoming places, in the context of Karachi.

This study investigates the kind of amenities required at bus stops to provide comfort to public. Moreover, it is researched as to how to make bus stops active places that foster community engagement and enhance rider experience.

Using qualitative analysis approach (observation, interviews), the research was carried out at two inner-city local bus stops of Karachi. The main focus of the research was the University Road, because of personal travelling and daily observation on this road by public transport. The stops selected for research were NIPA and Hassan Square, because these are most used locations on this main road.
\end{abstract}

The findings suggested that local bus stops of the city support interaction between people and are perfect incubators of life on streets. Through improvements to the existing condition of bus stops, they can contribute to the development of social ties and increase the use of local transport in the inner-city neighborhoods.

The study concludes that public bus stops are not only an important part of transport infrastructure but also serve as social nexus for people, where people gather, wait for buses, converse with their fellow riders and discuss different activities of their lives. If equipped with all necessary amenities, the bus stops can decrease the traffic load of the city because more people will be encouraged to use public transport and can fulfill much more than transportation needs; they can provide opportunity to different ethnic groups to mingle and stimulate social cohesion.

Keywords: Bus stops, community engagement, social ties, social nexus, social cohesion.

\section{INTRODUCTION}

Bus stops are essential elements of the public transport system. Bus stops are the means to maximize the vehicular capacity of the roads, avoid hectic situations, and prevent hindrance to the flow of traffic. They are a sign of communal identity, have distinct features to narrate and are observed first by the individual before travelling. Commuters interact closely at the bus stops where they assemble to wait. Bus stops also create important relations among different places but they are frequently disregarded and thought as secondary elements in the cityscape.

For operational purposes of public transport, there are three main kinds of stops: scheduled stops, at which the bus should stop irrespective of demand; or flag stop, at which the vehicle will stop only on request; and stops, at which a vehicle will stop anywhere along the designated section of the road on request (Wikipedia, 2017). For successful public transport system scheduled and request stops are preferable, not the hail and ride stops.

In the city of Karachi, public buses are the main means of travel. They are cheap and convenient, therefore are used by a majority of middle and lower class commuters. These is however, lack availability of proper and well-maintained bus stops. Bus stops designated by the transport authorities in Karachi are not in good condition. They have below standard designs and are not properly maintained. Garbage, grit, concrete and speeding cars surround them. Attention is not given to making them a better place for users (Figures 1 and 2). Because of this lack of attention, often the only

* Ar. Humaira Nazir, Lecturer, Sir Syed University of Engineering and Technology, Karachi, Pakistan.

Email correspondance: hami.nazir@gmail.com 
users are either stray dogs or bus stops are being used for sleeping or resting by pedestrians. Sometimes people come to rest there; some of them are drug addicts or beggars who use this place for rest and sleeping. Because of this scenario, commuters of the city are forced to wait on the main roads. They put their lives on risk while standing on main roads due to traffic chaos because they feel insecure, discomfort and stressed at bus stops. Adequate security is also a concern at bus stops and incidents of snatching have been reported.

By providing basic amenities like providing proper sitting spaces, water cooler facility, public toilets, lighting arrangement for night, security cameras and route maps with exact timing, the waiting for a bus can be made a pleasant and even interesting experience. On the other hand, some other activities that engage community with the place must be provided, because by engaging community with bus stops value can be added to the neighborhood. Community engagement can be enhanced by connecting bus stops with other activities like provision of reading material, an art gallery that promotes local artists having historical photographs to highlight history of that area and the whole city. By the provision of these facilities to the bus stops they can not only become better places, but this can also lead to the increase of use of public transport. Furthermore, it can provide the passerby with the chance to interact with their environment and to take care of it or at least appreciate it in a more relaxed way. It can also lead to the change in people's perception of what a bus stop can be. Thus, the bus stop can be a destination itself, it can be a hub for social interaction.

\section{RESEARCH METHODOLOGY}

The objectives of the research were attained by the data collected from primary and secondary sources. Secondary data was collected by reviewing the existing knowledge related to the study, which included published research papers, research reports, journal articles and online information.

The primary data was collected by qualitative research method, through interviews of commuters, bus drivers and non users sitting at bus stops. Open-ended questionnaire and personal observations formed the basis of primary data collection. Satellite maps were used to mark the location of the selected study area. The main objective of this mapping was to identify the connections between different bus stops, which helped to compare the issues of each stop on main University Road in Karachi.

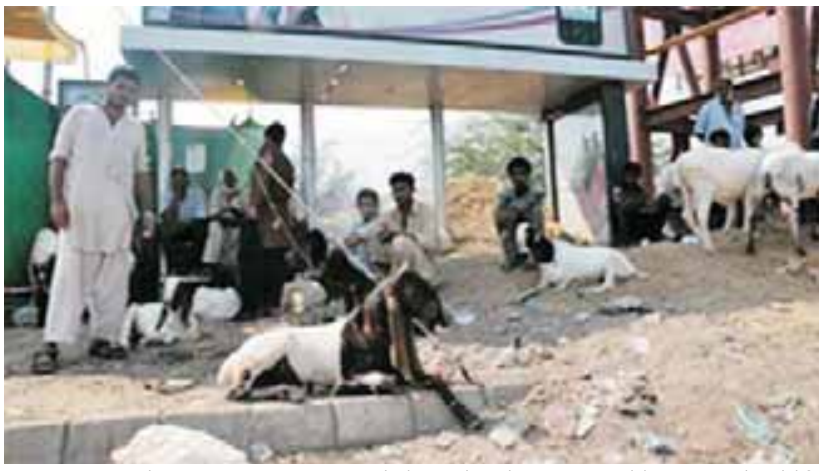

Figure-1: A bus stopnear Gara Kabristan has been turned into a makeshift cattle market. Theimage shows sacrificial animals and their owners waiting for buyers here on Sunday.

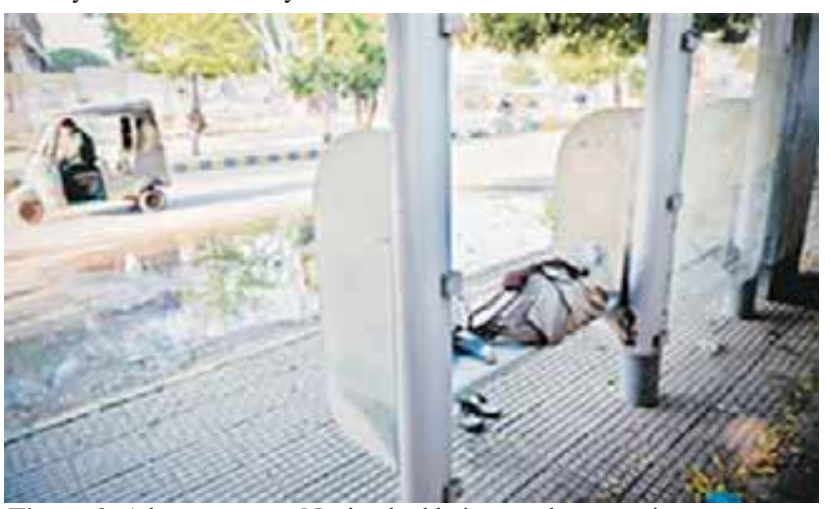

Figure-2: A bus stop near Nazimabad being used as a resting space.

The sample size for qualitative interviews was based on ten people, five from each selected area, drawn by simple random sampling. These included commuters from different age groups, in order to cover the different age groups using bus stops. Data was extracted from the bus stops through primary observations over a span of two days, including:

- Estimating the time the buses were stationary at the bus stops.

- Checking the number of passengers that get on the buses.

- Checking the number of passengers that descended the buses.

- $\quad$ Number of passengers that were still waiting once buses had left the stop.

- Non-bus stop users at the bus stop area.

- Average number of pedestrians that passed through the bus stop.

- Average numbers of beggars and hawkers using the bus stops.

The study was limited to the documentation of two selected bus stops. Suggestions and recommendations are included as 
part of the research proposal. These suggestions focus on the issues identified during the research and span around the problems faced by people on public bus stops and provision of best possible solutions to overcome these issues and make people feel comfortable with the use of public transport.

\section{LITERATURE REVIEW}

The best transit stop according to the literature reviewed, is one that fulfils all the needs of its users. In addition, it gives the users a sense of comfort and safety, and is connected to the surrounding neighborhood and community. The Delaware Valley Regional Planning Commission Report (2012), offers strategies for designing adequate bus stops. The guidelines provided in this document are very beneficial for a higher quality, consistent, accessible and better-connected network of bus stop facilities. Four elements that should be included in a transit stop as pointed out in this report are stop location, in-street design, curbside design and passenger amenities. These are detailed to make a neighbourhood bus stop and neighborhood itself a better place.

In an essay on Bus Transportation the author reviews the literature of Zegeer et. al. (2002), about bus stop design. Zegeer et. al. (2002), states that besides the bus stop signage a bus shelter with seating, trash receptacles and bicycle parking are also desirable features. In the design of a bus stop concerns about location, accessibility and improvement of bus stops should be addressed. He suggests that bus stops should be highly visible locations where pedestrians can reach easily by means of accessible travel routes. Therefore, a complete sidewalk system is essential to support a public transportation system. Convenient crossings are also important. He further suggests that proper placement of bus stops is the key to user safety. For example, placing the bus stops on the near side of the intersections or crosswalk may block pedestrians' view of approaching traffic, and approaching driver's view of pedestrians. At the same time approaching motorists may be unable to stop in time when a pedestrian steps from the front of a stationary bus into the traffic lane at the intersection. Far-side bus stops generally encourage pedestrians to cross behind the bus. Reallocating the bus stops to the far side of the intersection can improve pedestrian safety, since it negates the sight-distance restriction caused by the bus. Besides, Zegeer et. al., (2002) also suggests that bus stops should be accessible to pedestrians in wheelchair. For this bus stops should have paved connections to sidewalks where landscape buffers exist, and should not block pedestrian travel on the sidewalk (UK Essays, 2013).

Hanover Bus Stop Feasibility Study (2008), Steering Committee Report was prepared for Advance Transit to identify physical improvements to the streetscape environment of existing bus stops to make them more 'transit friendly,' while also addressing traffic congestion and pedestrian safety concerns. One of the strategies that was adopted to strengthen the use of the public transport in this report was to make bus stops more attractive place. The goals of this study were primarily to develop a program for bus stop improvements and enhancements that would achieve the major objectives of:

- Enhancing the rider's experience, becoming an attractive asset to the community;

- Takes about probable impacts of transport services on users;

- Develop rise in ridership and transport service.

The methodology used to conduct this research was observation and interviews on specific stops, with the focus of improvements to these stops. In addition, it was concluded that transit friendly bus stops were made by incorporating different elements, such as proper waiting areas, benches, signage, lighting and information board for route identification.

The quality and design of bus stops varies enormously, but all could benefit from a loving local touch. Dunham and LeBlanc (2013) investigate the factors which differentiate one bus stop from another, according to its context and location. They narrate that urban locations are frequently blessed with well-lit shelters, seats, route information and sidewalks. While suburban bus stops provide the greatest opportunities for healthy and convivial improvement, largely because the default condition is so unfriendly to begin with. They are often simply marked by a post in the ground with a sign of the local transit authority's logo and a well-worn patch of ground. School bus stops are the least marked since their locations are subject to most change. It doesn't take much to enhance a suburban bus stop. They conclude that everybody can easily celebrate the overlooked role of bus stops as both neighborhood gateway and communal gathering space. At the same time, modest difference can be made in the lives of the growing number of transit-users in one's neighborhood by addressing the design of bus stops.

This literature review provides techniques for making bus stops a better and attractive space, and ideas on improving the quality of the cityscape for both riders and community. The literature review also confirms that well designed bus stops play a vital role in strengthening the volume of traffic as well as in providing better services to the passenger. 


\section{DESCRIPTION OF THE SELECTED AREA}

\section{Location of area}

The areas selected for the study are shown in Figure 3. These two bus stops are NIPA Chowrangi and Hassan Square stops, located on main University Road in Gulshan-e-Iqbal Town (Figures 3 and 4).

\section{Present condition of Nipa Chrowangi bus stop}

At the NIPA Chowrangi bus stop the provision for sitting spaces is almost negligible. There is no evidence of any security. There are many open spaces which could be treated as green areas

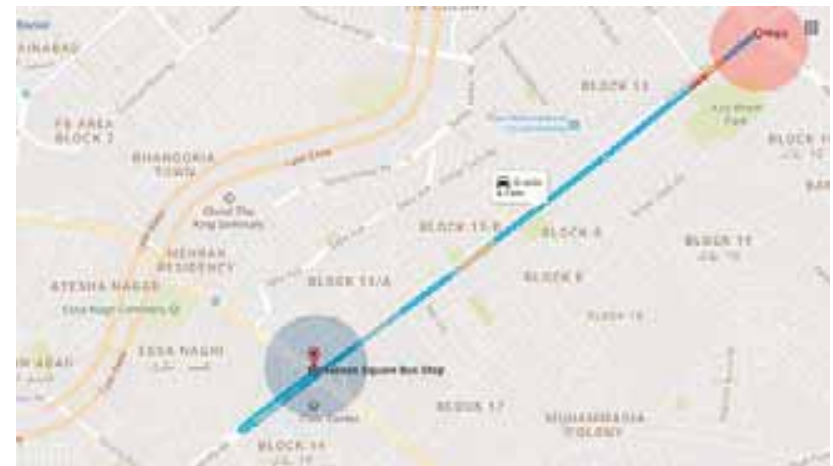

Figure-3: Showing the distance between Hassan Square stop and NIPA Chowrangi stop located on main University Road, Gulshan-e-Iqbal.

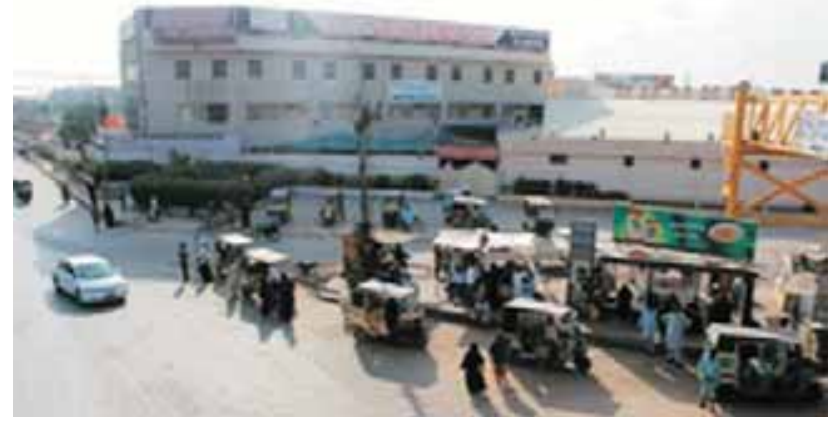

Figure-5: Insufficient sitting space at bus stop at NIPA Chowrangi.

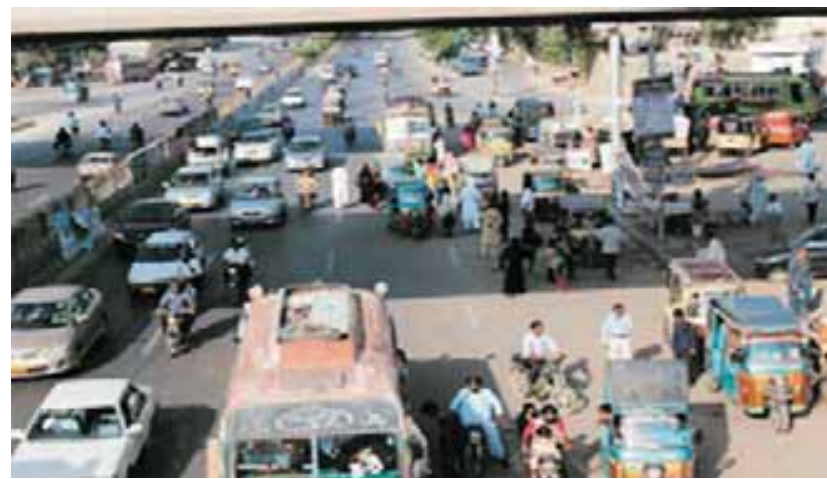

Figure-7: Presence of light and heavy vehicles around the NIPA Chowrangi stop. but right now they are being used only by hawkers and as parking stands. There is an absence of public toilet facility and newspaper racks at this stop which could add to the aesthetic quality of the bus stops (Figures 5-8).

\section{Present Condition of Hassan Square Bus Stop}

There is only one shelter provided on one side of the road at the Hassan Square bus stop, facing Jail Chowrangi. This indicates that the seating at the bus stop is not adequate. On the other side of the road there is no bus stop. People stand on footpath while waiting for the bus. One good point at this bus stop however is that there is a provision of eating area that

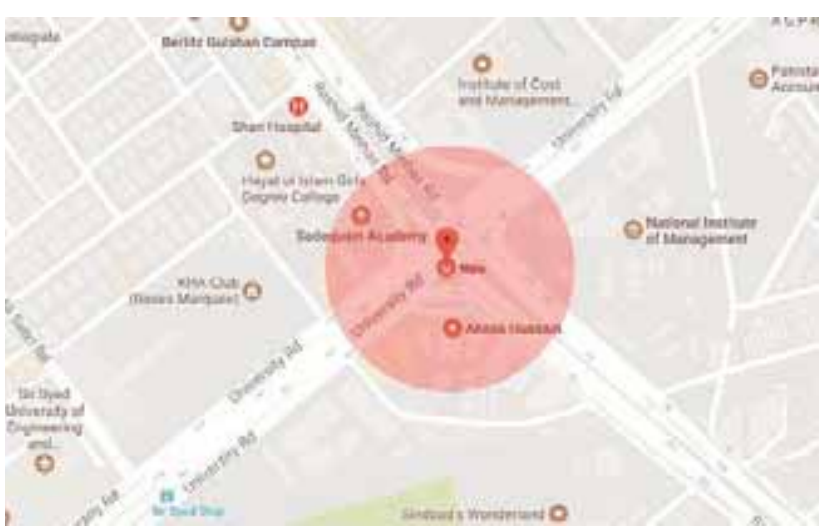

Figure-4: NIPA Chowrangi bus stop locaion.

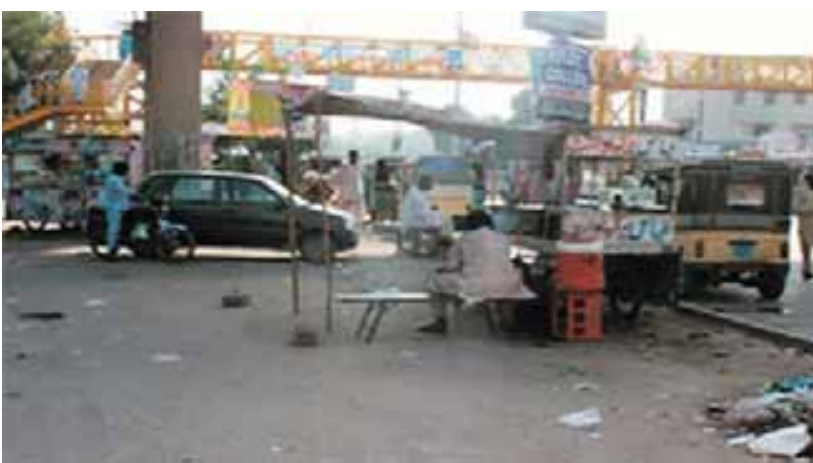

Figure-6: Different stalls for passengers.

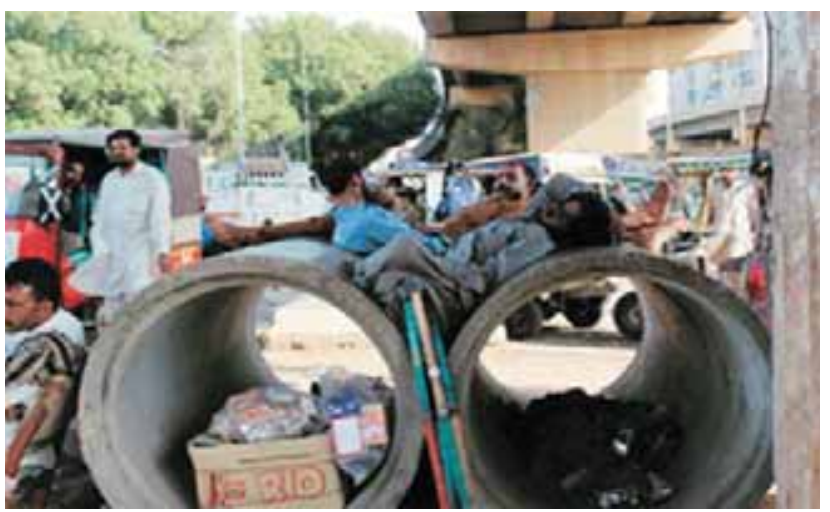

Figure-8: Presence of of druggies at NIPA Chowrangi stop. 
engages people at the stop. However, there is an absence of public toilets facility and newspaper rack which are some elements of bus stops that can add to the quality of space (Figures 9-13).

\section{FINDINGS AND ANALYSIS OF QUESTIONAIRE}

Lack of amenities at bus stops is one of the reasons why people choose not to ride via public transport. During peak hours, stops are overcrowded and can not provide shelter. Women are facing security and harassment issues. While studying bus stop design and their importance in the cityscape, it became noticeable that most of findings typically address the lack of amenities present at bus stops.

A well-designed bus stop can transform the experience of waiting for a bus into an entertaining, leisure space in the middle of the hectic rhythm of the city. An ideal stop is one that allows visibility and easy access to the bus, is comfortable and convenient, provides clear information, is safe and makes waiting for a bus a pleasant and even interesting experience. There is a need to explore factors that contribute to successful bus stops and create experiences that individuals can encounter while waiting for their buses.

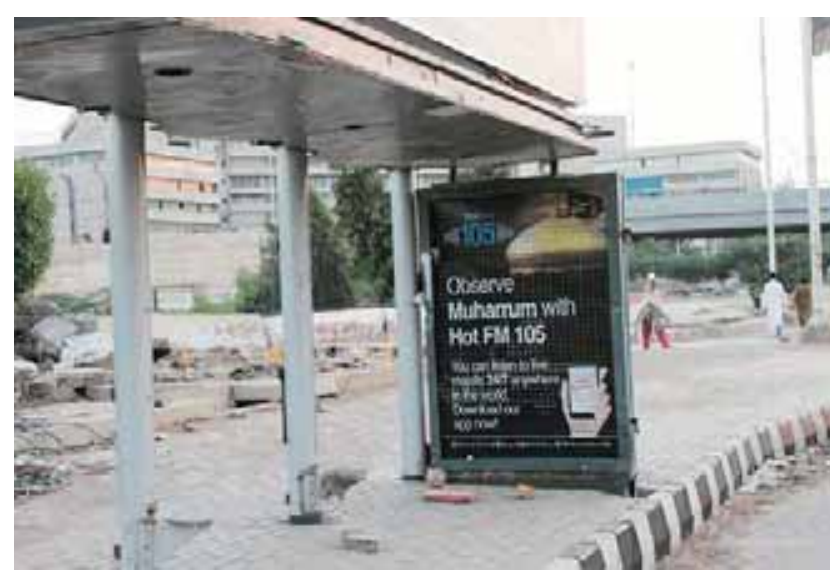

Figure-10: Bus stop without seating at Hasan Square.

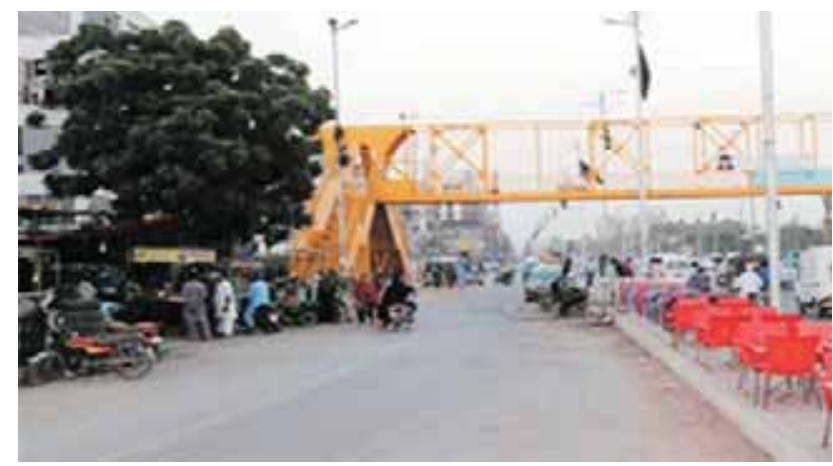

Figure-12: The eating area at the stop engages people while waiting for the bus.
Table 01 describes the problems identified by bus stop users in the two case study areas. These problems are listed and number of users who experienced these problems is tabulated.

The results of questions link to statement No. 1 indicating that majority of the respondents found the absence of schedule of buses as a major issue at the bus stop. Because of this they spent more time at the bus stops than actual travel time. The younger adults were more negative about bus travel in general and

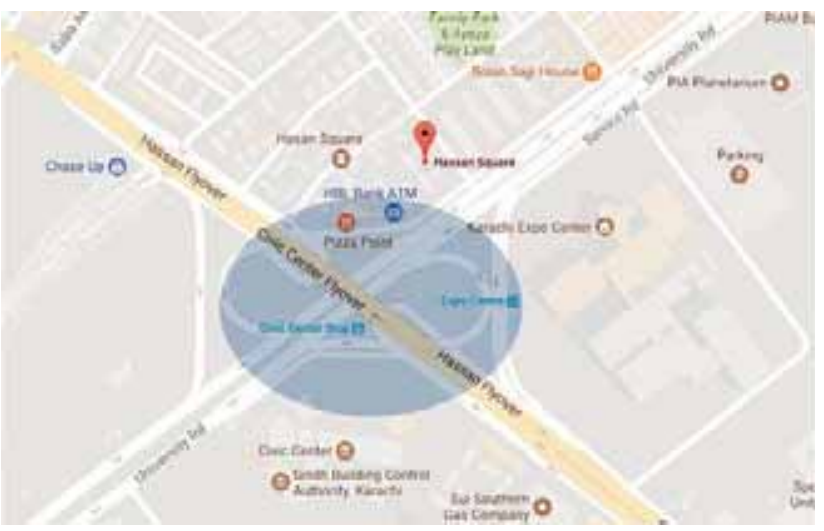

Figure-9: Showing Hassan Square bus stop location.

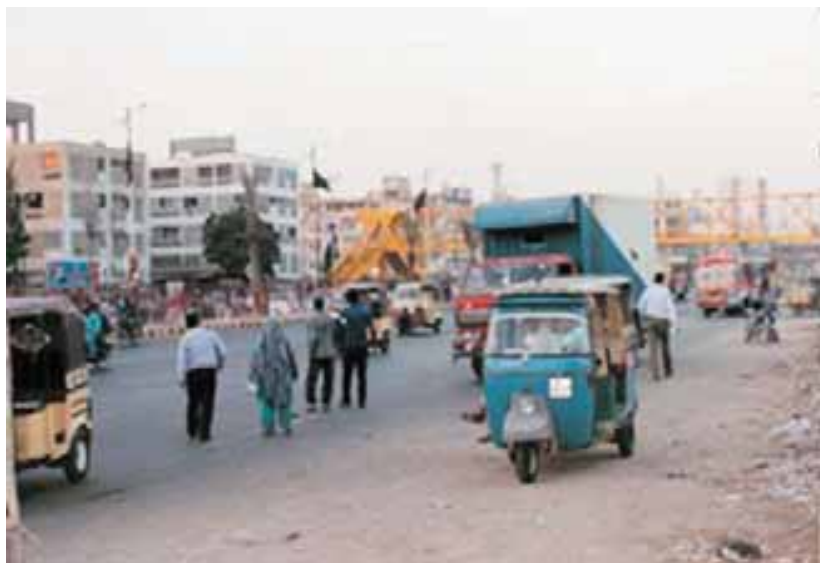

Figure-11: People are standing on the road while waiting for the buses.

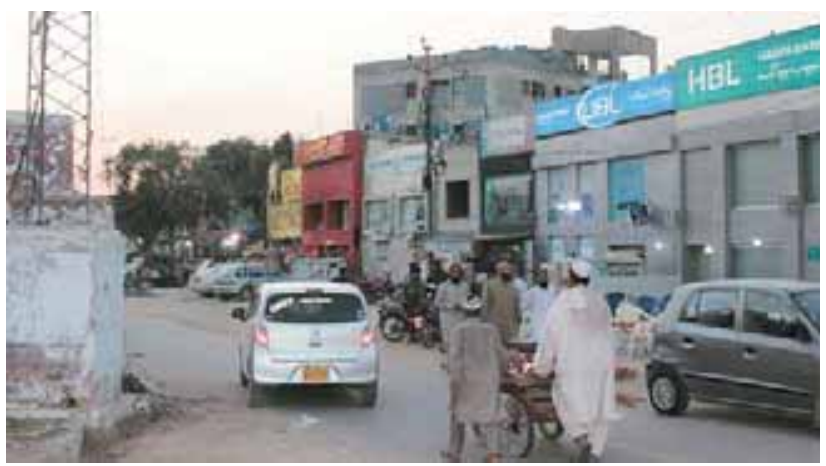

Figure-13: Commercial activities near the Hasan Square bus stop. 
angrier about delays and disturbance that occurs at stops. They said that delay or any disturbance resulted in important lectures being missed by them because they entered late in classrooms. Rest of the respondents faced different problems which are mentioned in Table 01 .

The results of questions link to statement No. 2 indicating that majority of respondents said that they do not feel secure at the bus stops and had bad memories due to threats of insecurity. Most of them had experienced snatching of personal belongings at the bus stops (Table 02). During the interviews one of the female commuter discussed her experience about long waiting time at the bus stop "It is a physical and mental torture for me to wait at the bus stop for long time period and on returning home I always have a bad mood and not capable of doing any other work." Another female mentioned her insecurity: "I do not feel secure because men in cars and on motorbikes stop and offer me lifts while waiting at bus stops".

Table 03 shows the essential amenities that commuters want at bus stops. The results of questions link to statement No. 3 which indicated that majority of the respondents thought that schedule of buses was essential part of bus travel because it saved their time. On the other hand some respondents said that they wished the public buses would at least stop at the designated places for two minutes. "It should be five minutes really, but I will be happy even if the buses stop for two minutes at the bus stops, which never happens in Karachi."

Table 04 shows the additional supportive amenities and activities that commuters desire at bus stops. The results of questions link to statement No. 4 which indicated that

Table-1: The problems identified by bus stop users in the two case study areas. These problems are listed and number of users who experienced these problems is tabulated.

\begin{tabular}{|l|l|c|c|}
\hline S. No. & \multicolumn{1}{|c|}{ Statement \# 1 Basic Problems regarding amenities at bus stop } & Yes & No \\
\hline 1 & Absence of sitting benches at some bus stops & 07 & 03 \\
\hline 2 & Insufficient seats to sit & 10 & 00 \\
\hline 3 & Males usually sit on provided seating & 05 & 05 \\
\hline 4 & Proper shelter is not provided on sitting place & 08 & 02 \\
\hline 5 & Absence of schedule for buses & 10 & 00 \\
\hline 6 & Absence of water cooler facility & 09 & 01 \\
\hline 7 & Facility of public toilet is not provided & 08 & 02 \\
\hline 8 & Absence of lighting arrangements for night & 07 & 03 \\
\hline 9 & Garbage dumped at stops & 06 & 04 \\
\hline
\end{tabular}

Table-2: Problems faced by commuters besides absence of amenities at bus stops.

\begin{tabular}{|c|l|c|c|}
\hline S. No. & \multicolumn{1}{|c|}{ Statement \# 2 Problems faced besides amenities at bus stop } & Yes & No \\
\hline 1 & Sexual harassment for females & 05 & 05 \\
\hline 2 & Insecurity, no protection against robbery and gun point snatching & 10 & 00 \\
\hline 3 & Presence of beggars and druggies & 08 & 02 \\
\hline 4 & Rickshaw stands at bus stops & 04 & 06 \\
\hline 5 & Long waiting time causing irritation and frustration & 07 & 03 \\
\hline
\end{tabular}

Table-3: The essential amenities that people would like to see at the bus stops.

\begin{tabular}{|c|l|c|c|}
\hline S. No. & \multicolumn{1}{|c|}{ Statement \# 3 Basic necessities at bus stop } & Yes & No \\
\hline 1 & Provision of sufficient sitting benches & 09 & 01 \\
\hline 2 & Distribution of sitting separate for males and females & 02 & 08 \\
\hline 3 & Provision of schedule for buses & 10 & 00 \\
\hline 4 & Proper shelter required on sitting place & 08 & 02 \\
\hline 5 & Water cooler facility & 05 & 05 \\
\hline 6 & Public toilet facility & 07 & 03 \\
\hline 7 & Requirement of lighting arrangements for night & 06 & 04 \\
\hline 8 & Provision of garbage bins & 08 & 02 \\
\hline
\end{tabular}


majority of the respondents wanted the installment of security cameras at the bus stops because they felt insecure while waiting at the stops.

Other respondents mentioned other additional facilities that they wanted to be a part of bus stops, like provision of Wifi, a small café and space for readers.

Table 05 documents the various activities that people engage in while waiting at bus stops. The results of questions link to statement No. 5 which indicated that majority of the people liked to spend their waiting time by socialising with others and in activities like observing people around them and chatting with fellow riders. Some people indicated that they liked smoking, using mobile phones and reading newspapers while waiting for the buses.

\section{RECOMMENDATION}

Based on the research a few suggestions can be made to improve bus stops of Karachi, and to make the city a better place for the commuters and contribute in the betterment of city's infrastructure. Within this context, there are some general qualities that any well-designed bus stop should have. The qualities that are described below are not meant to add public amenities at stops, but to increase the efficiency of existing amenities through design.

- Every stop should have a name, indorsing commuters' sense of their place in the city. At night, these signs should be easy to read, so they should have navigational value extending beyond transit. Routes should be numbered, mentioning the endpoint (indicating direction of travel) and the number of minutes until the next bus arrives. If commuters are aware of the network, they would be better informed about the arrival time of next bus.

- Bus stops must be provided with proper shelter, protecting commuters from harsh weather. Visibility is an important factor that needs to be considered in designing shade. It should not obstruct views of approaching buses.

- Accessibility is important in bus stop design because people like to be close to the point where the bus door will open, so they will be sure of getting on. The shelter should not obstruct process of boarding and people should be able to board the bus conveniently.

- Bus stops should be well lit and light fixtures should be provided and housed in protective casings to reduce vandalism. Waiting and boarding areas should be well illuminated. City's bus stops should be lighted at night by backlit advertising panels at an intensity of 20 lumens per square foot.

- $\quad$ People need to know when a bus will arrive and where it will go and the destination of the buses. Therefore putting up signage with schedule, route information and a map at the bus stops will enable commuters to

Table-4: The additional supportive amenities and activities that commuters desire at bus stops.

\begin{tabular}{|c|l|c|c|}
\hline S. No. & \multicolumn{1}{|c|}{ Statement \# 4 Addition supportive amenities and activities } & Yes & No \\
\hline 1 & Provision of telephone booth & 03 & 07 \\
\hline 2 & Provision of Wi-fi & 05 & 05 \\
\hline 3 & Provision of newspapers rack & 04 & 06 \\
\hline 4 & Provision of book cases & 02 & 08 \\
\hline 5 & Installment of cameras for security & 10 & 00 \\
\hline 6 & Rain and sewerage water drainage system & 07 & 03 \\
\hline 7 & Samll cafe & 08 & 02 \\
\hline 8 & Proper space for paddlers & 08 & 02 \\
\hline
\end{tabular}

Table-5: Activities that people engage in while waiting at bus stops.

\begin{tabular}{|c|l|c|c|}
\hline S. No. & \multicolumn{1}{|c|}{ Statement \# 5 Activities to spend waiting time } & Yes & No \\
\hline 1 & Chatting with fellow riders & 01 & 09 \\
\hline 2 & Smoking & 02 & 08 \\
\hline 3 & Hanging out with friends on telephone & 03 & 07 \\
\hline 4 & Keep quiet and observe activities around the stop & 08 & 02 \\
\hline 5 & Read a book or newspaper & 01 & 09 \\
\hline
\end{tabular}


know the desired information. Buses should operate on a fixed schedule, which should be fixed well in advance and should not change often, for the benefit of the habituated passengers. This will be beneficial not only for local users but also for tourists and for those who are unfamiliar with the city.

- For sufficient amount of seating, it is necessary to know the number of people who will use the stop and the amount of time they will spend for waiting. Where people wait for a long time, or where the bus stop is used by the elderly, more seating is generally needed than in areas where buses come more frequently. On the other hand, where there are large fluctuations between peak and off-peak use, a bus shelter can be designed with seating areas outside of the shelter to accommodate the differences.

- All bus stops must be provided with toilets and a maintenance structure should be in place. This facility can be nominally charged.

- At every stop, a security system with cameras should be installed to provide a sense of security.

- Seat designs should discourage people from lying down or to spend long extended times there.

- Location for bus stops could be near retail stores that have products desired by commuters and bus riders (e.g. bakery, flower shop, newsstand, etc.) and should remain open till late at night.

- Green elements, if incorporated at bus stops can contribute to the aesthetic appeal of the stops as well as enhance the overall experience of travel. Psychologically, green areas within city environments provide moments of much needed relief from the built up surroundings. Apart from dedicated park spaces, greenery can be accommodated through well-designed planters, trees and other hard landscape elements.
- $\quad$ Public telephone booths, WiFi facilities, newspaper racks and trash receptables are some other facilities that can be provided at the bus stops.

By providing these facilities for commuters at the bus stops they can be made into useful spaces that are used frequently and can encourage public transport use.

\section{CONCLUSION}

For running public transport efficiently in a city, supporting infrastructure is essential. One of the major infrastructure requirements are bus stops, and without these public transportation will not be able to run smoothly. The biggest city of Pakistan, Karachi requires well-maintained and properly marked bus stops. It is essential to address the bus stops as well as transit system for celebrating their purpose and to get expected freedom that they provide. However, the local bus stops can be as efficient as the city wants them to be. They can be celebrated more in city infrastructure if they are efficient. There is considerable research that shows that a well-maintained bus stop will be respected more and have less possibility of vandalism and other abuses than poorly maintained ones. The community's attitude towards using public buses can be examined through the conditions of public bus stops. It should be designed to reflect the city in which it is located. This can be achieved through the provision of all necessities and by the design details. Certain standards for bus stops can be adapted to reflect the unique characteristics of the area in which they are located.

A well designed bus stop can enhance the surrounding neighborhoods by acting as a place that connects the community through different activities. Communities can engage by provision of a café or a spot for performances, markets, and similar conveniences that also support the perception of the stop as more than just a stop. Strategies for vendors should be designed so that bus stops become lively places. 


\section{REFERENCES}

Delaware Valley Regional Planning Commission, 2012, "SEPTE Bus Stop Design Guidelines", [pdf] Philadelphia, viewed 2-10-2012, from https://strategic-plan/reports/SEPTA-Bus-Stop-Design-Guidelines.

Dunham, E., LeBlanc, J., 2013, "How to Adopt Your Neighbourhood Bus stop", viewed, 28-08-2017, from http://www.good.is/artile/how-to-adopt-your-neighborhood-bus-stop.

Hanover Bus Stop Feasibility Study, 2008, "Report to the Advance Transit" [pdf], viewed 21-09-2017, form http://www.dartmouth.edu/ opdc/planning/documents/HanoverBusStop.

UK Essays, November 2013, "Bus Stations Are the Most Important Transportation Infrastructure Tourism Essay”, [online]. viewed 21-10-2017, from https://www.ukessays.com/essays/tourism/bus-stations-are-the-most-important-transportation-infrastructuretourism-essay.php?cref $=1$.

Wikipedia, Bus stop. [online] viewed 15-09-2017.

Zegeer, C. Stewart, J. and Huang, H., 2002, "Safety Effects of Marked versus Unmarked Crosswalks at Uncontrolled Locations: Executive Summary and Recommendation Guidelines", Report No. FHWA-AD-01075, Federal Highway Administration, Washington DC. 